\title{
CIÊNCIA E METAFÍSICA NA TEORIA DA MEMÓRIA DE BERGSON ${ }^{1}$
}

\author{
Paulo César Rodrigues
}

UNESP-Marília

Resumo: Determinar a relação entre ciência e metafisica na teoria bergsoniana da memória parece ser bem mais problemático que expor, pura e simplesmente, o teor crítico com o qual o filósofo geralmente abordou tanto a ciência quanto a metafísica, em seu esforço de determinação do significado da lembrança e da natureza do reconhecimento. Sem dúvida, a relação que Bergson manteve, em toda sua obra, com as tradições científica e metafísica foi predominantemente polêmica. Contudo, a crítica não dissimula o uso positivo que ele fez da ciência para alimentar uma metafísica que vai de encontro às concepções tradicionais da atividade filosófica. Foi justamente a partir da apreciação crítica de ambas as atividades que o filósofo elaborou a ideia de uma metafísica regulada pelos fatos, isto é, de alguma maneira controlada pela experiência. Ao que tudo indica, Bergson quis liberar a metafísica do 'campo cerrado da dialética pura', tornando-a uma disciplina positiva, tal como as demais ciências. Com efeito, as hipóteses sustentadas no âmbito da teoria da memória não foram aventadas especulativamente e afirmadas dogmaticamente; foram, ao contrário, conclusões obtidas com base na crítica e na reinterpretação dos resultados da pesquisa científica, mais exatamente, da psicologia empírica. Neste sentido, a teoria de Bergson é, ao mesmo tempo, avanço teórico e correção das concepç̃es anteriores, na medida em que tais hipóteses metafísicas passam a orientar a leitura dos dados empíricos. É desta perspectiva que se pretende analisar a teoria da memória, a fim de compreender a relação entre ciência e metafísica como uma simbiose epistêmica.

Palavras-chave: Ciência; Experiência; Intuição; Memória; Metafísica.

Abstract: To determine the relationship between science and metaphysics in Bergson's theory of memory seems to be way more problematic than, quite simply, expose the critical content with which the philosopher has usually addressed both science and metaphysics, in the attempt to construct meaning of remembrance and recognition of nature. Undoubtedly, the relationship that Bergson maintained, throughout his work, with the scientific and metaphysical traditions, was highly controversy. Nevertheless, criticism does not conceal the positive use he made of science, in order to feed a metaphysics that goes against traditional conceptions of philosophical activity. It was precisely through the critical appraisal of

1 Este artigo resulta de um aprimoramento de um trabalho inicialmente apresentado no XVI Encontro Nacional de Pós-Graduação da ANPOF, em 2014. É, ainda, resultado parcial de uma pesquisa financiada pelo MCTI/CNPQ/Universal 14/2014.

(C) Dissertatio - Volume Suplementar 4, Dezembro - 2016 
both activities that the philosopher developed the idea of a metaphysics regulated by the facts, being somehow controlled by experience. As it seems, Bergson wanted to release the metaphysics from a 'closed field of pure dialectics', making it a positive discipline, such as the other sciences. Indeed, the hypothesis supported within the memory theory have not been speculatively raised nor dogmatically affirmed; on the contrary, they were conclusions based on criticism and reinterpretation of scientific research results, more precisely, empirical psychology. In this sense, Bergson's theory is, at the same time, theoretical advance and correction of previous conceptions, once metaphysical hypotheses tend to guide the reading of empirical data. It is from this perspective that we aim to analyze the theory of memory in order to understand the relationship between science and metaphysics as an epistemic symbiosis.

Keywords: Science; Experience; Intuition; Memory; Metaphysics.

'[...] la métaphysique n'a rien de commun avec une généralisation de l'expérience, et néanmoins elle pourrait se définir l'expérience intégrale" ${ }^{\prime 2}$

\section{I}

O que normalmente se entende por ciência e metafísica, na filosofia de Bergson, remete a duas competências cognitivas heterogêneas, as quais mobilizam diferentes 'atividades do pensamento'. A inteligência constrói a inteligibilidade de seu objeto por meio de operações conceituais concatenadas. Mais fundamentalmente, todas essas operações implicam um meio espacial no qual se pode estabelecer distinções e relações abstratas. A intuição, por sua vez, como 'método' da metafísica (BERGSON, 2001b; DELEUZE, 1999), reclama um 'contato' com o objeto de conhecimento ('contato' que deve se realizar tanto na intuição sensível quanto na intuição interna, isto é, na intuição propriamente metafísica, no sentido 'técnico' que Bergson lhe empresta). Não é outro, aliás, o significado do chamado 'empirismo radical' que alguns dos intérpretes mais expressivos da filosofia de Bergson encontraram em sua obra (DELEUZE, 1999; PRADO JR., 2004; WORMS, 1997). É certo que não se trata unicamente do reconhecimento da centralidade da 'experiência' no processo cognitivo, o que sem dúvida também ocorre: 'A verdade é que uma existência só pode ser dada numa experiência’ (BERGSON, 2001b, p.1292). Se há radicalidade no empirismo bergsoniano é porque se rejeita toda construção teórica, todo esquema de inteligibilidade meramente simbólico, articulado pelo sujeito justamente para assimilar a irremediável dispersão da experiência

\footnotetext{
2 Bergson, La pensée et le mouvant, 2001b, p.1432.
} 
através de formas cognitivas estáveis. É preciso frisar que em Bergson, ao menos no domínio da metafísica, o conhecimento não consiste numa construção intelectual, mas numa 'simpatia', numa apreensão da própria 'carne' da realidade ${ }^{3}$.

Caracterizar ciência e metafísica implica, portanto, dimensionar inicialmente a distância que as separa. Se a noção de experiência estabelece um elo entre as duas atividades, nem por isso se pode pensá-las a princípio no mesmo plano. Muitas passagens de La pensée et le mouvant - mormente do ensaio 'Introduction à la métaphysique' -, incitam a ver entre as duas disciplinas uma incompatibilidade metodológica e mesmo gnosiológica (BERGSON, 2001b, p.1392-1396). Incompatibilidade metodológica, sem dúvida, pois ciência e metafísica se servem de métodos radicalmente distintos e mesmo opostos; incompatibilidade gnosiológica, também, uma vez que a própria concepção de conhecimento que nelas figura difere profundamente. A experiência metafísica certamente não pode ser obtida por meio da generalização de dados empíricos, de um alargamento horizontal da experiência científica. Sustentar semelhante tese acarretaria uma concepção indutivista demasiadamente ingênua da atividade filosófica e, possivelmente, também da ciência. Por outro lado, fundar a validade de enunciados metafísicos no plano da experiência, através de verificação experimental, redundaria numa concepção hipotético-dedutiva da metafísica, o que seguramente trai o espírito e a letra do pensamento bergsoniano. Se, por um lado, Bergson é o proponente de uma 'metafísica positiva' (BERGSON, 2001b, p.1424); por outro, nunca escondeu o teor intuitivo e especulativo de seu pensamento filosófico, fazendo-o passar ao largo dos recursos da 'inteligência discursiva' e da ciência. Nada parece indicar uma continuidade epistêmica entre as duas disciplinas, recobrindo os dois 'lados' do Absoluto (matéria e espírito) ${ }^{4}$, conforme a expressão de Deleuze (DELEUZE, 1999, p.25). Ao contrário, em grande medida, o trabalho crítico que permeia a obra de Bergson ataca justamente a universalização do método das ciências naturais, o qual fora aplicado de modo inadvertido igualmente aos domínios psíquico e biológico (o psíquico e o vital são, essencialmente, objetos da metafísica),

\footnotetext{
${ }^{3}$ No artigo Le tournant de l'experience, Renaud Barbaras explora a apropriação merleaupontyana de Bergson e Husserl, identificando em suas filosofias uma unidade de intenção: a de 'voltar às coisas mesmas'. Declara Barbaras: '[...] é verdade que, desde o início, Merleau-Ponty recepciona a fenomenologia husserliana e o pensamento de Bergson como duas tentativas essenciais de retorno às coisas que, como tal, convidam a uma confrontação' (BARBARAS, 1997, p.33).

${ }^{4}$ Semelhante repartição não é de todo justa, porque negligencia o fato de haver, em Bergson, uma metafísica da matéria, assim como há, também, uma 'ciência do espírito' ou, melhor, de um aspecto do espírito: a psicologia.
} 
conforme testemunham abundantes exemplos na psicologia científica e na biologia evolucionista. Importa ressalvar: o ideal moderno de mathesis universalis não seduz o autor de Matière et mémoire.

Desde o Essai sur les données immédiates de la conscience, define-se a atividade científica por meio de dois procedimentos fundamentais: 'medir e prever' (BERGSON, 2001a, p.150). As ciências comprometem-se com a redução da natureza a um sistema de forças mensuráveis e calculáveis, a partir do qual se possa formular juízos preditivos. É notável como a matematização dos dados e a previsibilidade conectam a ciência moderna à noção de técnica ${ }^{5}$, denunciando a vocação essencialmente prática desse tipo de conhecimento e justificando por que ele é 'apreciável por seus êxitos ou sua eficácia' (DELEUZE, 1999, p.25). Inversamente, a metafísica é caracterizada como um saber desinteressado que se obtém por intermédio de um esforço de intuição, por uma interiorização que redunda em coincidência com a temporalidade geradora do objeto 6 : '[...] o tempo é o que se faz, e mesmo o que faz com que tudo se faça' (BERGSON, 2001b, p.1254). A distância que separa ciência e metafísica é, portanto, a mesma que separa inteligência e intuição, o conhecimento externo (en-dehors) do conhecimento interno (au-dedans), o procedimento que vai dos 'conceitos à realidade' do procedimento que vai da 'realidade aos conceitos'; enfim, o saber que aborda 'coisas prontas' do saber que apreende o 'impulso' (élan) que as engendra. Circundar o objeto de conhecimento, multiplicar indefinidamente os atos judicativos que dele se apoderam caracterizam o saber científico, sempre cumulativo e perfectível. Coincidir com o objeto, adotar seu 'ritmo de duração', acompanhar as sinuosidades de seu movimento gerador designa o saber metafísico, curiosamente também declarado por Bergson como cumulativo e passível de retificação, um inacabável empreendimento coletivo, tal como a ciência (BERGSON, 1001b, p.1285-6; BERGSON, 2001c, p.817-8). Embora haja uma considerável diferença entre saber científico e saber metafísico, cada um deles pondo em execução um modus operandi específico e obtendo resultados

\footnotetext{
${ }^{5}$ A respeito disso, Frédéric Worms observa: '[...] nossa percepção, e com ela nossa ciência e nossa técnica, permanecerão sempre fundadas nas coisas, sobre as quais elas asseguram, imediatamente, uma aplicação teórica e uma tomada prática. Toda ação e todo saber humanos estão assim fundados de um só golpe por Bergson' (WORMS, 1997, p.79).

${ }^{6}$ Tal constatação pode ser identificada desde o início da obra de Bergson, na descrição dos sentiments esthétiques, por exemplo. Cf. Essai, p. 09-17. Segundo a interpretação que Bento Prado Jr. faz dos sentiments esthétiques: '[...] é a descrição que repete a temporalização através da qual o objeto vem ao ser. [...] É o próprio objeto que é esta gênese, que é este constante ato de autoconstituição que jamais atinge a cristalização inerte do dado. A duração é a lei de um universo sempre em vias de constituição. Ela é este movimento de um objeto que vem ao ser, sem jamais deixar de estar vindo' (PRADO JR., 1989, p.85-6).
} 
díspares, as duas disciplinas parecem confluir em algum ponto, à medida que elaboram conhecimentos com o mesmo estatuto epistemológico: conhecimentos provisórios, retificáveis, e, ao mesmo tempo, 'absolutos' (BERGSON, 2001b), cada um deles exibindo adequação em seus respectivos domínios. Mais ainda, o desenvolvimento de ambos parece exibir interferências recíprocas. Isso significa que o curso do desenvolvimento científico absorve algo e altera o curso do desenvolvimento metafísico, e viceversa. Julga-se aqui que semelhante constatação ficará clara no exame da relação entre psicologia e metafísica, ou seja, no estudo da memória.

A explícita heterogeneidade entre ciência e metafísica, de um lado, e as indicações mais ou menos implícitas de uma colaboração entre as duas atividades, de outro, introduzem algo de paradoxal nesta discussão. O que dizer, então, destes paradoxos: se o saber metafísico remete a uma 'experiência integral', como pode haver retificação em seu interior? $\mathrm{Ou}$ ainda, mais fundamentalmente, se ciência e metafísica designam duas modalidades de conhecimento essencialmente distintas, ancoradas em capacidades cognitivas heterogêneas, as quais, a bem da verdade, impulsionam o pensamento para direções opostas, como Bergson pôde aproximá-las, a ponto de sustentar uma 'metafísica positiva', balizada pelas orientações da experiência, inclusive científica?

\section{II}

A relação entre ciência e metafísica parece exprimir bem o duplo movimento que Deleuze identificou em todo o pensamento bergsoniano: um movimento de disjunção, 'separação do misto'; e outro de convergência, estreitamento ou reunião, num plano mais alto ou mais primitivo, do que fora separado (DELEUZE, 1999, p.20). A teoria da memória exprime esse duplo movimento do modo mais exemplar (de início, separação entre percepção e lembrança e, no domínio exclusivo da memória, entre o elemento fisiológico e o componente psíquico ou espiritual; posteriormente, confluência dos disjuntos na experiência concreta). Não é outra a razão pela qual ela representa o momento privilegiado para esmiuçar a relação entre ciência e metafísica ${ }^{8}$,

7 É preciso sublinhar que 'experiência', em Bergson, não designa a mesma coisa nos planos da ciência e da metafísica. Num caso, trata-se da experiência externa, sensivel; noutro, da experiência interna, imediata ou intuitiva.

8 Convém registrar que se pode encontrar semelhante relação também na teoria da vida (Cf. artigo de Silene Torres Marques, 'Significação da vida e liberdade: ciência e metafísica na filosofia de Bergson') e na própria compreensão do mundo físico (Cf. Frédéric Worms na obra Bergson ou les deux sens de la vie, ao tratar da termodinâmica, p.242-3). Contudo, é na teoria da memória que ocorre, mais explicitamente, a restrição de um problema metafísico a um problema experimental, recolocando-o no 'terrain des faits' (BERGSON, 2001d, p.165). A propósito, vale dizer que o segundo capítulo de Matière 
para além das frequentes indicações, na própria obra de Bergson, que evidenciam uma acentuada distinção entre as duas modalidades de conhecimento, de sorte a sugerir uma impermeabilidade epistemológica que desmentiria todos os pontos de contato eventualmente estabelecidos (ciência e metafísica estando separadas como se separa o conhecimento objetivo do subjetivo, a análise da intuição, a experiência externa da experiência interna etc.). $\mathrm{Na}$ teoria da memória, entretanto, ao mesmo tempo que se demarca a especificidade dos dois tipos de pesquisa a respeito das funções psicológicas9 (a da psicologia ou ciência e a da filosofia ou metafísica), constata-se, igualmente, reciprocidade entre elas: 'Justamente porque elas estão no mesmo nível, têm pontos em comum e podem, nesses pontos, verificarem-se uma pela outra' (BERGSON, 2001b, p.1286). Como Bergson bem pontua, no prefácio à sétima edição de Matière et mémoire, ciência e metafísica se articulam no estudo da natureza da lembrança:

Ora, desde que pedimos aos fatos indicações precisas para resolver o problema
[problema metafísico da relação da alma com o corpo], é para o terreno da
memória que nos vemos transportados. [...] Não apenas os documentos são aqui
de uma abundância extrema (que se considere somente a massa formidável de
observações recolhidas sobre as diversas afasias!), como em nenhuma outra
parte quanto aqui a anatomia, a fisiologia e a psicologia conseguiram prestar um
apoio mútuo (BERGSON, 2001d, p.164-5).

Dessa maneira, um problema metafísico passa a ser tematizado à luz das aquisições das ciências empíricas, conferindo à própria metafísica um teor positivo ausente em sua fase dogmática. Mais ainda, a novidade aloja-se no fato de Bergson recolocar a metafísica no âmbito da 'experiência possível' ou, mais exatamente, no da 'experiência real', removendo a inclinação transcendente que Kant apontara no uso de seus conceitos: '[...] ciência e metafísica diferirão de objeto e de método, mas se comunicarão na experiência' (BERGSON, 2001b, p.1287), assevera Bergson, na segunda Introdução à La pensée et le mouvant.

A afirmação de uma metafísica capaz de se beneficiar dos resultados científicos _ encontrando nos dados experimentais da ciência a base empírica

et mémoire fora publicado numa revista científica (editada por Theodule Ribot), ao passo que trechos do quarto capítulo foram publicados numa revista de metafísica (editada por Félix Ravaisson). (Cf. WORMS, 1997, p.07-8).

${ }^{9} \mathrm{Na}$ teoria da memória, ciência (leia-se, doravante, psicologia) e metafísica compartilham o mesmo objeto. Eis aí mais um componente que assegura o privilégio desse tópico da obra bergsoniana na elucidação da relação entre ciência e metafísica. No prefácio de Matière et mémorie, Bergson declara: 'Como seria diferente, se a psicologia tem por objeto o estudo do espírito humano enquanto funcionando utilmente para a prática, e se a metafísica é apenas esse mesmo espírito humano fazendo um esforço para se desprender das condições da ação útil e para se reapreender como pura energia criadora?' (BERGSON, 2001d, p.167). 
de suas formulações — não significa, entretanto, compactuar com uma concepção indutivista, reproduzindo em seu interior um 'empirismo' que procede do fato para a lei, dos dados particulares para os enunciados universais. Trata-se, essencialmente, de atribuir à metafísica a capacidade de engendrar conhecimento a partir de um tipo específico de experiência, normalmente estabelecida por meio da crítica aos procedimentos e aos resultados da investigação científica, como se verá, mais adiante, neste artigo. Não é o caso, por conseguinte, de encontrar em proposições empíricas a confirmação de convicções especulativas. Aqui como alhures, o elemento principal que denuncia uma insólita comunicação subterrânea entre as duas disciplinas é a fidelidade à experiência, ao vivido $(v e ́ c u)^{10}$; bem como a relevância do papel da crítica na elaboração discursiva do conhecimento ${ }^{11}$. $\mathrm{O}$ resultado disso será uma verdadeira simbiose, no plano epistêmico, entre saber empírico e saber especulativo, revelando surpreendentemente que o saber especulativo é também tributário da experiência.

Reduzindo a teoria da memória ao '[...] ato concreto pelo qual recuperamos o passado no presente' (BERGSON, 2001d, p.235), a saber, ao reconhecimento - fenômeno que exprime o funcionamento efetivo da memória -, removem-se, logo de início, as pretensões universalistas e abstratas de uma suposta teoria geral da memória, uma metafísica novamente calcada no conceito como ideia geral. De fato, o que Bergson faz é investigar a natureza da memória nos planos da experiência normal e patológica, comum e experimentalmente controlada. Sua intenção é a de elaborar uma teoria que dê conta de elucidar o significado da lembrança, sem recorrer a formulações teóricas desacompanhadas de evidências experimentais, tal como ordinariamente procedeu a metafísica. É nesse contexto que se dá a consulta ao acervo de teorias científicas atinentes à memória. Julga-se, no entanto, que não é o conjunto dos resultados empíricos da psicologia que fomenta as formulações teóricas de Bergson. Sua inspeção da psicologia parece ser, desde o início, orientada por hipóteses metafísicas já formuladas, muito embora tais hipóteses dependam, de alguma maneira, de um assíduo contato com os fatos (BERGSON, 2001b, p.1432). Dissipa-se assim a ideia de uma metafísica inteiramente arrancada, por indução, dos dados de uma disciplina científica,

10 Bergson afirma, ainda no prefácio de Matière et mémoire: 'Não teríamos acreditado, no início de nossas pesquisas, que pudesse haver qualquer conexão entre a análise da lembrança e as questões que se agitam entre realistas e idealistas, ou entre mecanicistas e dinamistas, a respeito da existência ou da essência da matéria' (BERGSON, 2001d, p.167).

$11 \mathrm{Em}$ todas as obras de Bergson, com efeito, o saber metafísico se articula por meio de uma inspeção crítica da ciência. Neste sentido, o discurso filosófico depende fundamentalmente da crítica, para ser elaborado. Cf. Franklin Leopoldo e Silva, Bergson: intuição e discurso filosófico, p.29-94. 
configurando uma espécie de 'meta-psicologia'. Ao que tudo indica, o mesmo movimento que afasta a metafísica bergsoniana de uma concepção hipotéticoindutiva a aproxima de uma concepção hipotético-dedutiva. Neste caso, o método científico estaria florescendo em solo filosófico. O ideal cartesiano de 'unidade do saber' estaria sendo reafirmado, sub-repticiamente, como unidade metodológica.

Será que isso realmente se confirma na filosofia de Bergson? Ao menos no âmbito do segundo capítulo de Matière et mémoire, tudo leva a crer que o filósofo elabora uma metafísica hipotético-dedutiva, efetivamente análoga às teorias hipotético-dedutivas das demais ciências. Logo no início do segundo capítulo do livro, três hipóteses metafísicas são expostas, das quais se deduzem consequências experimentalmente verificáveis, sendo a verificação experimental decisiva para lhes averiguar a validade. As três hipóteses são: 1) o passado sobrevive em 'mecanismos motores' e em lembranças subjetivas; 2) o reconhecimento dá-se por movimentos do corpo e por evocação de lembranças; 3) há passagem gradual e insensível das lembranças subjetivas, distribuídas no tempo, para os 'esquemas motores', sediados no corpo (BERGSON, 2001d, p.224-5). Em seguida, Bergson assevera: 'Resta saber se a experiência verifica essas três proposições' (BERGSON, 2001d, p.225). A argumentação posterior pretende aquilatar tais hipóteses; demonstrar, ao mesmo tempo, sua 'precisão' e denunciar a incongruência dos postulados tradicionais da psicologia com a experiência. A argumentação se desenvolve, portanto, em duas vertentes: uma positiva e outra negativa. Na vertente positiva, trata-se de evidenciar como a experiência comum e sobretudo científica corrobora as hipóteses elencadas acima. Na vertente negativa, faz-se a crítica à postura hegemônica em psicologia (atomismo associacionista e localizacionismo cerebral das lembranças). Convém acrescentar, de resto, que os dois movimentos se desenvolvem de forma entrelaçada. Ao mesmo tempo que o filósofo se atribui a tarefa de solapar os postulados metafísicos tácitos que alimentam a psicologia experimental, oferece uma metafísica 'alternativa' para a própria psicologia interpretar seus dados, desta vez, acredita-se, de modo mais 'preciso', mais próximo da real natureza de seu objeto.

Com a releitura dos dados experimentais, Bergson pretende, de um só golpe, demolir ao menos duas convicções basilares da psicologia empírica e avaliar experimentalmente suas próprias teses (as três hipóteses mencionadas acima). Os dois postulados que comumente orientam as pesquisas sobre a memória na psicologia inquirida por Bergson são: a) o reconhecimento se realiza por associação de uma percepção com uma lembrança; b) a lembrança encontra-se localizada no cérebro, de maneira que uma lesão do cérebro acarretaria a destruição das lembranças correspondentes e a impossibilidade de 
reconhecer um objeto percebido. É notável o caráter metafísico de tais assertivas, a primeira delas diretamente herdada do empirismo inglês; a segunda, legada pela metafísica moderna sob a forma de paralelismo psicofisiológico (BERGSON, 2001c, p.843-846). É notável, também, a ligação interna entre elas, exemplarmente exposta nesta passagem de Matière et mémoire:

Refugiaremos na hipótese cômoda de traços cerebrais que coincidiriam, de
movimentos cerebrais que o exercício facilitaria, ou de células de percepção
comunicando-se com as células onde repousam as lembranças. A bem dizer, é
em hipóteses psicológicas desse gênero que acabam se perdendo, querendo ou
não, todas as teorias do reconhecimento. Elas querem fazer sair todo
reconhecimento de uma aproximação entre a percepção a lembrança; mas, por
outro lado, a experiência está aí, testemunhando que, mais frequentemente, a
lembrança só surge uma vez tendo sido reconhecida a percepção (BERGSON,
2001d, p.237).

Explicar o reconhecimento, psicologicamente, por meio de uma associação entre percepção e lembrança, assim como explicá-lo, fisiologicamente, pelas conexões entre células perceptivas e mnemônicas, não se sustenta na própria consideração dos casos clínicos investigados pela psicopatologia. Tudo se passa como se a psicologia produzisse resultados experimentais a partir de postulados teóricos postos em xeque pelos próprios resultados experimentais por ela obtidos. A necessidade de reformulação dos princípios metafísicos norteadores da pesquisa psicológica faz-se, portanto, urgente, visto que Bergson desnuda a incompatibilidade entre teoria e dados experimentais.

Examinando mais de perto o modus operandi da psicologia, observa-se que o erro fundamental a contaminar toda a investigação repousa na confusão entre hábito e lembrança. O psicólogo deposita uma ênfase excessiva na memória adquirida por esforço repetido, incrustrada no corpo pelo hábito. Posteriormente, assume este tipo peculiar de retenção do passado - que, a bem dizer, recobre uma pequena parte da atividade mnemônica -, como modelo para toda forma possível de memória. Há aqui, visivelmente, a mesma 'generalização apressada' que se constatou, no Essai, na abordagem crítica da psicofísica $^{12}$. Quando a psicologia concebe a lembrança como um 'hábito contraído', como uma impressão que se grava quanto mais se repete, ignora que a maior parte da atividade da memória registra acontecimentos únicos. Se a psicologia presta mais atenção às lembranças adquiridas por esforço repetido e não às lembranças espontaneamente acumuladas, é porque aquelas são mais

${ }_{12} \mathrm{Cf}$. A crítica à psicofísica, a qual se estende por quase todo o primeiro capítulo do Essai, p. 17-50. Cf., também, o artigo 'Henri Bergson e a crítica à psicologia científica', publicado em 2011, na revista Princípios. 
úteis do que estas à elucidação do relacionamento prático do organismo com o mundo. Sendo a psicologia uma disciplina que estuda o espírito humano engajado na ação, na vida prática, não poderia deixar de confundir a lembrança com o 'mecanismo motor' articulado no corpo para responder, praticamente, a uma solicitação do ambiente, exibindo na resposta um uso adequado da experiência passada. Ao confundir a parte fisiológica da memória com sua totalidade, o psicólogo pavimenta o caminho para o localizacionismo. Neste movimento, a lembrança fatalmente acabará sendo concebida como uma estrutura neurológica, inscrita nas células do córtex cerebral:

Será preciso supor, portanto, que o mecanismo cerebral, medular e bulbar, que serve de base ao hábito motor, é ao mesmo tempo o substrato da imagem consciente. Donde a estranha hipótese de lembranças armazenadas no cérebro, que se tornariam conscientes por um verdadeiro milagre, e nos reconduziriam ao passado por um processo misterioso (BERGSON, 2001d, p.235).

Mas a dimensão fisiológica da memória, efetivamente afirmada por Bergson, é apenas a parte da memória que fixa no corpo a influência do passado sob a forma de 'esquema motor'. Tais 'mecanismos' visam unicamente à adaptação do organismo às circunstâncias que lhe são impostas pela presença dos objetos. Como eles são produzidos na experiência de percepções repetidas, facilmente se conclui, com a psicologia do século XIX, que é a repetição da percepção que preside o processo de acumulação de lembranças no cérebro. E o reconhecimento, então, só poderia ser explicado através de uma associação entre o estado perceptivo e o estado mnemônico, que, em última análise, exprimiria apenas a articulação de elementos fisiológicos. As patologias da memória não fariam outra coisa senão desarticular tais elementos, perturbando a harmonia entre lembrança e percepção, ao romper o elo associativo. A psicologia empírica advoga semelhante ponto de vista, sem atentar para as incongruências com os dados experimentais.

$\mathrm{Na}$ cegueira psíquica, por exemplo, que é a incapacidade de reconhecer os objetos visualmente percebidos, a psicopatologia encontra tãosomente uma perturbação da capacidade de associar uma lembrança visual à imagem atualmente percebida. Ora, se o reconhecimento de um objeto é apenas uma associação, uma articulação entre a memória visual e o estado perceptivo, ao menos duas consequências dessa hipótese deveriam ser verificadas na experiência. São elas: a) todo caso de cegueira psíquica deve vir acompanhado de inibição da memória visual; b) toda inibição da memória visual deve ter como efeito a cegueira psíquica. Acontece que os casos clínicos extraídos da literatura especializada e analisados em Matière et mémoire não 
confirmam tais consequências ${ }^{13}$. Ao contrário, testemunham a favor de pelo menos duas das hipóteses metafísicas formuladas por Bergson (enunciadas mais acima como 1 e 2). Com efeito, constatou-se na cegueira psíquica que os pacientes que a apresentavam ostentavam uma memória visual inalterada. Eram capazes de descrever em detalhe sua cidade ou um objeto qualquer. Todavia, quando colocados diante deles, não os reconheciam. Comportavamse como se estivessem pela primeira vez na presença de tais objetos. Se as crenças da psicopatologia estivessem corretas, deveria haver nesses casos perda significativa da memória visual. Inversamente, num caso analisado por Charcot, no qual o paciente parecia ter perdido todas as suas lembranças visuais, verificou-se que nem por isso ele se viu impedido de reconhecer algumas percepções (não reconhecia sua cidade, mas reconhecia ruas, avenidas, edifícios; não reconhecia seus filhos, porém, sabia que eram crianças etc.). Se o reconhecimento nasce de uma ligação da lembrança com o estado perceptivo, a perda absoluta da memória visual deveria implicar a perda absoluta da capacidade de reconhecer. Mas o que se observou, ao contrário, foi a preservação de um certo reconhecimento 'impessoal e anônimo', o qual não convoca o auxílio de lembranças visuais.

O que tais casos clínicos testemunham é que a hipótese da psicologia associacionista não se confirma no plano dos fatos. O reconhecimento não nasce de uma associação de lembranças e percepções. Os doentes, por vezes, preservaram suas lembranças visuais e, mesmo assim, não conseguiram reconhecer os objetos percebidos; ou então, inversamente, perderam suas lembranças visuais e, no entanto, mantiveram parte de sua capacidade de reconhecer. O que concluir de tais constatações empíricas?

Concluamos [com Bergson] que nem todo reconhecimento implica sempre a intervenção de uma imagem antiga, e que se pode também fazer apelo a tais imagens, sem conseguir identificar as percepções com elas (BERGSON, 2001d, p.238).

É preciso estabelecer que o reconhecimento é, a princípio, um fenômeno de ordem corporal ou motora (BERGSON, 2001d, p. 238-242). Ele não faz intervir imagens-lembranças mais ou menos esclarecidas, mais ou menos nítidas. É uma atitude do corpo diante de um objeto ou, para usar a linguagem bergsoniana, um 'acompanhamento motor' (BERGSON, 2001d, p. 239). Daí haver sempre, na cegueira psíquica, um 'sentimento de desorientação’. O que a doença afeta é a relação entre a percepção e os mecanismos motores, os quais dispõem o corpo de modo a se adaptar ao objeto percebido. O reconhecimento é, antes de tudo, desempenhado pelo

${ }^{13}$ Cf. os casos de Wilbrand, Müller-Lissauer e o de Charcot, em Matière et mémoire, p. 237-239. 
corpo: 'Reconhecer um objeto usual é saber servir-se dele' (BERGSON, 2001d, p.239). Há uma dimensão funcional da memória anterior ao próprio advento do sujeito psicológico, na medida em que é o próprio corpo que, de início, reconhece. Neste sentido, o passado não sobrevive apenas como lembrança, mas também como 'esquema motor', como esboço de ações articuladas. Antes de tudo, o reconhecimento não é uma associação entre dois estados representativos (perceptivo e mnemônico), mas uma tendência motora, uma disposição corporal que assegura a familiaridade com o objeto presente. É isso que explica, segundo Bergson, os casos clínicos mencionados acima.

No entanto, não é somente ao corpo que a teoria bergsoniana do reconhecimento remete. Ao atacar o localizacionismo cerebral, Bergson passa a defender o lado subjetivo da memória, a lembrança propriamente dita, como a segunda instância na qual o passado sobrevive. Importa destacar que os argumentos apresentados até aqui ainda não atingiram, de modo decisivo, esse segundo postulado da psicologia. Fruto da confusão da totalidade da memória com sua parte motora, tal postulado assevera que as lembranças estão registradas nos próprios tecidos cerebrais, de sorte que a danificação de tais tecidos acarretaria a perda das lembranças neles encravadas. Ocorre que, também aqui, a experiência não verifica semelhante hipótese. Alega-se, juntamente com a psicofisiologia, que os casos de acidentados que lesionaram o cérebro e, consequentemente, perderam parcial ou totalmente suas lembranças, endossam a tese localizacionista. Bergson, ainda concebendo a memória como uma função psicológica, declara que a lesão de fato obstrui a lembrança, mas unicamente porque ela não consegue mais aderir ao esquema fisiológico, comprometido pela lesão ${ }^{14}$, para tornar-se efetiva. Se o reconhecimento atento e consciente exprime um processo de atualização de lembranças num mecanismo motor, montado no sistema nervoso, segue-se que a destruição de tal mecanismo interrompe justamente a extremidade fisiológica do processo de atualização, impedindo que a lembrança seja resgatada do passado e inserida no presente ativo do corpo.

A integridade da base orgânica é, portanto, condição necessária para o bom funcionamento da memória. Contudo, isso não implica que a realidade da memória seja inteiramente fisiológica. Na verdade, o que Bergson extrai do exame da psicopatologia é a afirmação de que toda perturbação do reconhecimento resulta sempre de uma doença do corpo. Nas patologias da

14 Contra o localizacionismo cerebral, Bergson afirma: 'A pretensa destruição das lembranças pelas lesões cerebrais é apenas uma interrupção do progresso contínuo pelo qual a lembrança se atualiza' (BERGSON, 2001d, p.270). 
memória, o desarranjo é sempre fisiológico, uma vez que a doença não pode afetar a lembrança propriamente dita, justamente por se tratar de um tipo de realidade de outra ordem, não mais física, mas virtual. Isso implica que o reconhecimento deve ser, mais que uma aptidão meramente fisiológica, uma atividade psicológica, que lança imagens-lembranças em direção ao 'mecanismo' articulado no sistema sensório-motor (BERGSON, 2001d, p.292).

Seguramente, os estudos interdisciplinares acerca das afasias (anatomia, fisiologia e psicologia) constituem o terreno mais fértil para os propósitos crítico e propositivo da filosofia de Bergson ${ }^{15}$. O exame das afasias (em sentido amplo, a incapacidade de se expressar pela fala, escrita ou sinalização; incapacidade de reconhecer a linguagem falada, escrita ou sinalizada) permitiu constatar que o esquecimento abrupto (normalmente provocado por um trauma) ou progressivo (geralmente resultado de uma doença degenerativa) das palavras exprime sempre um descompasso entre o estímulo sensorial e o esquema motor que deverá escandi-lo. Os numerosos casos mencionados por Bergson ambicionam mostrar que, nas afasias, não há destruição das lembranças das palavras. Na surdez verbal, que é a incapacidade de reconhecer a imagem acústica das palavras, o paciente também não reage a um estímulo intenso, embora conserve o sentido da audição em perfeito estado, evidenciando que o estímulo sensorial auditivo não mais se articula com a reação motora. Noutro caso, o doente diz que percebe uma conversa, mas como um ruído confuso, porque não consegue decompô-la a ponto de identificar frases, palavras e sílabas na 'massa sonora' ouvida. Enfim, não consegue estabelecer um 'acompanhamento motor' adequado ao estímulo recebido. Também aqui, todos os casos clínicos citados confirmam que a doença só afeta o esquema motor. Na verdade, desarticula estímulo sensorial e reação motora. Assim, a doença é bem mais um desarranjo funcional do que um comprometimento de tecidos do sistema nervoso (muito embora, em certos casos, tal comprometimento de fato ocorra ${ }^{16}$ ). A desarticulação das 'conexões sensório-motoras', as quais devem acompanhar a audição da linguagem, obstrui o fluxo de lembranças que normalmente aderem aos mecanismos corporais (BERGSON, 2001d, p.259), impedindo, dessa forma, o reconhecimento das palavras. Em todo caso, nas afasias, assim como nas lesões cerebrais, não são as lembranças das palavras, hipoteticamente

15 São variados os argumentos utilizados por Bergson para refutar a tese localizacionista e demonstrar suas próprias hipóteses: a do reconhecimento motor e a da passagem gradual das imagens-lembranças ao esquema corporal. A exposição, aqui, se concentrará no essencial do argumento. Cf. p.253-269.

${ }^{16} \mathrm{Cf}$. a passagem em que Bergson observa que muitas afasias vêm acompanhadas de danificação da 'primeira ou segunda circunvoluções têmporo-esfenoidais esquerdas' (BERGSON, 2001d, p. 271). 
armazenadas no cérebro, os elementos efetivamente abolidos, mas a capacidade de atualizar tais lembranças, inserindo-as no mecanismo motor correspondente.

Sabe-se que os estudos de Ribot $^{17}$ apresentam os dados decisivos nesta questão. Suas pesquisas evidenciaram que, nas afasias progressivas, há uma ordem invariável no esquecimento das palavras. Novamente aqui, observa-se que a psicofisiologia corta na própria carne ao produzir seus dados experimentais, já que os fatos clínicos por ela angariados conflitam com seus princípios teóricos. O esquecimento progressivo das palavras, percorrendo uma ordem invariável, depõe contra, naturalmente, a tese localizacionista. Nas afasias, o que progressivamente se perde não é uma sequência de conteúdos psicológicos (substantivos próprios, substantivos comuns, adjetivos e verbos), hipoteticamente inscritos nas células cerebrais. O que ocorre é uma degradação paulatina da função psicológica de evocação das lembranças. Como tal função está comprometida com a '[...] lei fundamental da vida, que é uma lei de ação' (BERGSON, 2001d, p. 291), as estruturas linguísticas que mais dificilmente se traduzem em ação (nomes próprios) são as que se apagam primeiro; ao contrário, as que mais se aproximam da ação (verbos) são as que se removem por último. O que depreender deste fato, senão que o reconhecimento é, antes de tudo, uma 'tendência motora' e que a lembrança não pode estar localizada no cérebro? A plausibilidade da hipótese localizacionista é posta em xeque exatamente porque não é verossímil que a doença atinja componentes neurológicos numa sequência regular, em todos os casos. Enfatiza Bergson:

Como explicar que a amnésia siga aqui uma marcha metódica, começando pelos nomes próprios e finalizando pelos verbos? Não se veria como, se as imagens verbais realmente se depositassem nas células do córtex: não seria estranho, com efeito, que a doença afetasse sempre essas células, na mesma ordem? Mas o fato se esclarecerá se se admitir conosco que as lembranças, para se atualizarem, têm necessidade de um coadjuvante motor, e que elas exigem, para serem evocadas, uma espécie de atitude mental inserida, ela própria, numa atitude corporal. Então os verbos, cuja essência é exprimir acoões imitáveis, são precisamente as palavras que um esforço corporal nos permitirá apreender, quando a função da linguagem estiver perto de nos escapar: ao contrário, os nomes próprios, sendo de todas as palavras as mais afastadas dessas ações impessoais que nosso corpo é capaz de esboçar, são aquelas que um enfraquecimento da função atingiria em primeiro lugar (BERGSON, 2001d, p.265).

17 A progressiva perda das lembranças nas afasias segue, segundo Ribot declara na obra Les maladies de la mémoire, a seguinte ordem: substantivos próprios, substantivos comuns, adjetivos e verbos. Tal constatação ficou conhecida como 'lei de Ribot'. Cf. Worms, 1997, p.130. 
Como se vê, novamente aqui, os fatos não confirmam a lei; mas, ao contrário, reivindicam novas formulações teóricas, as quais realmente deem conta de explicar os dados coletados.

A contradição implicada na tese localizacionista é flagrante: os psicólogos que sustentaram o localizacionismo se viram obrigados a ora confundir os centros mnemônicos com os centros perceptivos, ora a distinguilos. Se, de fato, a percepção permanece no cérebro sob a forma de lembrança, segue-se que os elementos nervosos envolvidos em seu armazenamento devem ser os mesmos que a percepção inicialmente impressionou, pois o que explicaria o deslocamento de região cerebral, quando o estado perceptivo passa para o estado de lembrança? Ora, se os elementos nervosos são os mesmos, por que a perda da lembrança decorrente de lesão em tais elementos não redundaria, igualmente, na diminuição da capacidade de perceber?'18 'A cegueira psíquica não impede de ver, tampouco a surdez psíquica de ouvir' (BERGSON, 2001d, 271). Nas patologias da memória, verifica-se, em certos casos, que o paciente perde a totalidade das lembranças visuais ou auditivas, todavia, nem por isso perde os sentidos da visão e da audição. Diante desta constatação, o psicólogo reconhece a necessidade de distinguir os centros perceptivos dos mnemônicos, sediando-os em regiões diferentes do cérebro. Mas tal hipótese não é mais plausível que a anterior, posto que a experiência psicológica revela que há passagem gradual de uma lembrança para uma percepção ${ }^{19}$, ao passo que a psicologia apreende tais estados como 'coisas feitas'. Se lembrança e percepção encontram-se em regiões diferentes do cérebro, como poderiam se comunicar, como poderia haver o reconhecimento de um objeto familiar? A conclusão negativa que se segue naturalmente dessas contradições é: a lembrança não pode ser fisiológica, não pode estar armazenada no cérebro. Em última análise, pensar a localização é reafirmar o associacionismo, visto que a ideia de estados cerebrais que se conectam regata o vocabulário associacionista, desta vez sob uma indumentária fisiológica. Não é outra coisa o que Bergson afirma, nesta passagem importante:

É, portanto, em vão que se tratará imagens-lembranças e ideias como coisas feitas, às quais se atribui em seguida um lugar em centros problemáticos. Por

18 Cabe perguntar, no mesmo sentido de Sartre, por que em nossa experiência subjetiva não confundimos uma percepção com uma lembrança, ou melhor, uma percepção fraca com uma lembrança vivida? Diz Sartre, referindo-se à distinção entre imagem e percepção: 'E por que a imagem de um tiro de canhão não aparece como um pequeno estalo real? Como se explica que nunca tomemos nossas imagens por percepções?' (SARTRE, 2013, p.82).

${ }^{19}$ Não se acompanhará aqui a ampla discussão acerca da 'evocação das lembranças', isto é, do modo como uma lembrança adere ao mecanismo motor montado no corpo. A descrição do processo de atualização das lembranças pode ser encontrada em quase todo o terceiro capítulo da obra. Cf. p.276316. 
mais que a hipótese esteja disfarçada sob uma linguagem emprestada da anatomia e da físiologia, não é outra coisa que a concepção associacionista da vida do espírito; exprime apenas a tendência constante da inteligência discursiva de fragmentar todo progresso em fases e solidificar em seguida essas fases em coisas; e como ela nasceu, a priori, de uma espécie de preconceito metafísico, não tem nem a vantagem de seguir o movimento da consciência nem a de simplificar a explicação dos fatos (BERGSON, 2001d, p.269-270).

Em última análise, portanto, o localizacionismo cerebral resolve-se numa versão fisiológica do associacionismo clássico, diretamente derivado do empirismo inglês.

O itinerário crítico que se acaba de percorrer pretende dar conta de refutar algumas convicções da psicologia experimental. A significação metafísica da lembrança passa a ser afirmada sobre os escombros da concepção 'materialista' sustentada pela ciência. Se, no segundo capítulo do livro, Bergson se ocupou em dizer o que a lembrança não é, no terceiro, declara o que ela é, em seu sentido mais genuíno, em sua pureza metodologicamente reconquistada. É o próprio mode d'être da lembrança - sua dimensão metafísica, que complementa a inspeção crítica das concepções científicas ${ }^{20}-$, que será afirmado após a passagem pela psicologia. A lembrança pura, com efeito, exprime a 'sobrevivência em si do passado'. A refutação do localizacionismo cerebral permitiu a Bergson assegurar que '[...] a lembrança pura, ao contrário, não interessa a nenhuma parte de meu corpo' (BERGSON, 2001d, p.281-2). Ela não se localiza em lugar algum, justamente porque não ocupa espaço. A crítica aos postulados da psicologia foi animada pela ideia de que há uma dimensão da memória irredutível a elementos fisiológicos ou espaciais. Tal ideia se viu endossada pelos dados empíricos da própria psicologia, de modo que a refutação de seus postulados teóricos possibilitou a Bergson afirmar a realidade espiritual ou, mais exatamente, temporal da lembrança. Se a lembrança não é cerebral e nem espacialmente localizada é porque ela é espiritual e temporalmente situada.

Com efeito, a lembrança pura é 'passado'; portanto, não pode ser assimilada como um dado espacializado, uma vez que somente o presente, o atual, encontra-se no espaço. Bergson dá razão a Kant quando este definiu o espaço como 'forma de simultaneidade'. Já o passado puro, a lembrança pura, supõe o tempo ou, antes, exprime uma realidade temporal, um modo de existência virtual ${ }^{21}$. Worms observa, com razão, que: 'O fato da memória se

20 Worms, todavia, considera a teoria da 'lembrança pura', exposta no terceiro capítulo de Matière et mémoire, ainda uma teoria psicológica, pois trata sobretudo do 'funcionamento da vida mental'. Cf. Introduction à Matière et mémoire de Bergson, p.138.

21 Importa dizer que o virtual, em Bergson, opõe-se ao atual, mas não ao real. 0 virtual designa um tipo de realidade ou de existência que consiste num paradoxal repouso ativo: repouso, pois não é atuante, 
apoia, pois, sobre o fato ainda mais primitivo do escoar do tempo' (WORMS, 1997, p.98). Em última análise, o que sustenta a teoria da memória é a 'duração', assim como a duração só é o que é porque é essencialmente memória: 'Sem esta sobrevivência do passado no presente, não haveria duração, mas somente instantaneidade' (BERGSON, 2001b, p.1411). Para Bergson, o passado permanece integralmente como virtualidade. E o virtual é o inativo, uma vez que toda atualidade se manifesta materialmente numa ação. Bergson insiste neste ponto: há diferença de natureza entre percepção e memória, porque a natureza da percepção é ativa, realiza-se no presente; ao passo que a realidade da lembrança é impotente, dá-se no passado. A memória, em seu sentido puro, é o que não atua mais, assim como a percepção é a mais pura atualidade, inserção ativa no mundo. Como a vida mental está inteiramente voltada para a ação, não atuar mais equivale a não existir. $O$ esforço de Bergson consistiu em mostrar que impotência ou inatividade não significam inexistência. É forçoso admitir um tipo de realidade que não participa da matéria ou da ação, mas, mesmo assim, participa da existência, possui uma realidade que não pode ser negligenciada impunemente. Tal é a natureza da realidade virtual que define a memória propriamente dita. De direito, se não de fato, todas as experiências da consciência sobrevivem integralmente como virtualidade, com lembranças puras ${ }^{22}$.

\section{III}

Neste momento já é possível retomar a questão que orienta a presente leitura da teoria da memória. Se há, como se acabou de ver, uma relação intrínseca entre crítica e metafísica — à medida que a denúncia da inexatidão da apreciação científica acerca da natureza da memória retifica a metafísica que ulteriormente irá nutrir a própria ciência —, cabe recolocar aqui a pergunta acerca da relação entre ciência e metafísica na filosofia de Bergson, uma vez que não é admissível sustentar, no contexto dessa filosofia, uma aplicação simples do método experimental à especulação filosófica. Sem dúvida, nem modelo hipotético-indutivo nem modelo hipotético-dedutivo dão conta de elucidar o procedimento da metafísica positiva asseverada por

não se exprime em ação no presente; ativo, pois mobiliza seu conteúdo em direção ao presente, tende a se atualizar, ao menos parcialmente.

${ }^{22}$ Até mesmo neste ponto delicado de sua obra, em que teses metafísicas audaciosas são afirmadas, Bergson não se afasta demasiadamente da experiência. Menciona os casos de enforcamentos e afogamentos, em que os sobreviventes relatam que, por um breve momento, tiveram acesso à totalidade de suas lembranças. Cf. Matière et mémoire, p.295. Alhures, refere-se também, en passant, às aquisições teórico-experimentais da psicanálise, cujo processo terapêutico consiste em resgatar lembranças removidas da consciência, encontrando aí mais uma evidência da preservação do passado. Cf. La pensée et le mouvant, p.1316. 
Bergson. A especificidade metodológica das duas disciplinas é preservada, e mesmo a índole _ ora empírica, ora especulativa _ dessas atividades teóricas aparentemente tão díspares permanece devidamente resguardada. Por outro lado, a cumplicidade identificada entre elas está ligada às noções de crítica e experiência. Ou seja, é a avaliação crítica que se faz da ciência, de seus princípios e de sua interpretação dos dados experimentais, que possibilita liberar o pensamento para tematizar o que a ciência não pode compreender no interior de seu rígido enquadramento conceitual. E liberar o pensamento é liberar a experiência de suas restrições sensíveis e intelectuais.

No estudo da memória, a crítica da ciência desenvolve, negativamente, o que a metafísica irá propor positivamente. Ao dizer o que a memória não é, diz-se, quase ao mesmo tempo, o que ela é. Se o segundo capítulo da obra é eminentemente crítico, pautado pela inspeção dos dados positivos da psicofisiologia, isso se deve ao fato de o terceiro capítulo pretender afirmar teses metafísicas que seriam incompreensíveis sem que uma prévia explicitação das incongruências às quais o ponto de vista científico fatalmente conduz seja realizada. A crítica, portanto, prepara os ouvidos para a recepção das sentenças metafísicas. Sem esse trabalho prévio, tais sentenças se reduziriam a asserções dogmáticas, novamente vulneráveis ao jogo antinômico de teses e antíteses. Vinculando-as à ciência, ao contrário, as convicções metafísicas poderão ser fortalecidas por evidências empíricas, ao passo que a ciência _ mormente a psicologia _, uma vez permitindo ser iluminada por tais convicções, poderá interpretar de modo mais "preciso" os dados experimentais que coleta. Como negar que há aqui permeabilidade e mesmo reciprocidade entre as duas disciplinas? Conforme salienta Bergson, "[...] como o espírito e a matéria se tocam, metafísica e ciência poderão, ao longo de sua superfície comum, provar-se uma pela outra, esperando que o contato se torne fecundação" (BERGSON, 2001b, p. 1286-7). Sem dúvida, não pode haver incompatibilidade entre ciência e metafísica porque ambas descrevem a mesma realidade, cada uma delas atentando para uma das duas direções em que a realidade se desenvolve: tension e extension, espírito e matéria.

E é justamente na experiência que o espírito e a matéria se tocam. Em Matière et mémoire, Bergson insiste que a experiência é um "misto", um misto de percepção e lembrança, matéria e espírito ${ }^{23}$. Resulta daí uma experiência do real marcada pelo interesse prático. A experiência metafísica, por sua vez, deve

${ }^{23}$ Vale dizer, neste ponto, que as teorias da percepção pura e da lembrança pura, ambas desenvolvidas em Matière et mémoire, constituem as duas "tendências puras" de cuja mistura nasce a experiência ordinária, essencialmente pragmática. Isoladas, cada uma delas conduz, respectivamente, à realidade da matéria e do espírito. 
se estabelecer à medida que rompe com os quadros da experiência convencional, seja ela científica, seja comum. Tal ruptura, contudo, depende do exame crítico da ciência, o qual deve ser radical o bastante para atingir não somente os postulados e os resultados científicos, mas também, e sobretudo, o próprio procedimento geral desta atividade: compreender o real no interior de uma experiência mista. O tema do tournant de l'expérience é tão significativo em Bergson (cf. DELEUZE, 1999; BARBARAS, 1997) porque remete a duas direções passíveis de serem percorridas pelo pensamento: a experiência mista ou científica e a experiência pura ou metafísica, a "cristalização inerte do dado" e seu movimento gerador ${ }^{24}$. Se é possível inverter a direção natural da experiência, necessariamente tributária do interesse prático, é porque, em grande medida, a crítica autoriza desarticular o que o pensamento analítico laboriosamente estabeleceu. Se se trata de uma construção, feita pelo sujeito do conhecimento, ele mesmo, o sujeito do conhecimento, pode desfazê-la, para obter então uma experiência pré-conceitual, pré-lógica; numa palavra, uma experiência imediata da realidade (BERGSON, 2001b, p.1270). No caso pontual da teoria da memória, a inspeção crítica da postura hegemônica em psicologia (associacionismo e localizacionismo) pretendeu obter uma experiência não pragmática (mista), mas metafísica (pura), da lembrança ${ }^{25}$, uma "experiência integral" do passado em si. Neste sentido, a metafísica "positiva" advogada por Bergson pode ser assim chamada porque ainda está conectada à experiência, porém, a um tipo de experiência que não se confunde com a experiência científica e, não obstante, dela parte.

A metafísica se instala, portanto, numa experiência inaudita, viabilizada pela suspensão da experiência comum e científica, mas também por um ato intuitivo, uma abertura imediata para o imediato. Assim, a teoria metafísica é elaborada a partir da inspeção crítica do pensamento conceitual que encontra na atividade científica sua expressão mais genuína —, e da admissão de uma experiência que inverte sua direção habitual, abandonando o pragmático e o útil para buscar o "originário". Seguramente, não se pode passar da análise para a intuição ${ }^{26}$, da inteligência discursiva para o ato de coincidência com a atividade que se dá abaixo da estabilidade dos dados

24 O tema do tournant remete, com efeito, a uma experiência originária, anterior à própria constituição da experiência humana, esta última sempre inclinada no sentido da utilidade. Cf., Matière et mémoire, $\mathrm{p}$. 321.

25 Os "dois sentidos da vida", discriminados por Worms na filosofia de Bergson, podem ser compreendidos como dois níveis ou direções da experiência: o pragmático e o metafísico. Cf., especialmente, o capítulo 3 de seu livro Bergson ou les deux sens de la vie, intitulado exatamente "Os dois sentidos da vida".

26 "[...] da intuição pode-se passar à análise, mas não da análise à intuição" (BERGSON, 2001b, p. 1413). 
empíricos disponíveis à inspeção conceitual. Por isto, dizer que a filosofia deve partir da ciência não significa, absolutamente, concebê-la como um "resumo" ou uma "síntese" do saber científico ${ }^{27}$. Significa apenas que não se pode apreender o dado intuitivo diretamente, sem o auxílio de "conhecimentos materiais", uma vez que o objeto da intuição é, em si mesmo, intraduzível para as categorias do pensamento discursivo. A apropriação filosófica de um objeto de conhecimento é indireta, de certa maneira dependente dos recursos da inteligência. Neste sentido, as ciências oferecem ao filósofo alguns pontos sólidos sobre os quais ele pode se apoiar para atravessar o fluxo da experiência em direção a sua pureza originária. O tema da "virada" (tournant) só é factível, em Bergson, do interior da própria experiência. Se é a crítica da experiência pragmática que libera sua envergadura metafísica, segue-se que para reencontrar a cumplicidade entre ciência e metafísica é preciso manter-se na imanência da experiência. Somente assim será possível reapreender o ato gerador por trás da solidez das coisas "já feitas", bem como dos conceitos que as traduz simbolicamente. Percorrer o caminho que vai da ciência à metafísica é percorrer o caminho que vai do dado ao ato que o engendra ${ }^{28}$. E tal ato é a própria duração.

Assim, a experiência metafísica é sempre integral, porque é principalmente experiência da duração, da totalidade temporal que constitui o espírito e a matéria. Entretanto, "experiência integral" não significa em Bergson experiência acabada, perfeita, posto que se está diante de uma realidade permanentemente "em vias de constituição". O ideal de "precisão", tão caro ao pensamento bergsoniano, exprime tão-somente a coincidência ou adequação completa entre a apreensão e o objeto apreendido, de tal modo que o conhecimento, no caso da metafísica, adere ao seu objeto, acompanha sua evolução, desvela sua natureza movente. É nesse sentido que Bergson afirma que tanto o saber metafísico quanto o científico "tocam o absoluto" (BERGSON, 2001b, p.1280). Há saber absoluto sempre que houver adequação entre os procedimentos empregados na inspeção cognitiva e a própria natureza do objeto investigado. Afirmar um saber absoluto não redunda numa concepção por assim dizer estática do conhecimento metafísico ou científico, fixados em princípios apodíticos ${ }^{29}$. Por ser sobretudo o

27 "Mas a intuição metafísica, embora só se possa chegar a ela a força de conhecimentos materiais, é outra coisa que o resumo ou a síntese desses conhecimetnos" (BERGSON, 2001b, 1432).

${ }^{28}$ Desde a teoria das multiplicidades, Bergson já distinguia o dado do ato, o objetivo do subjetivo, na construção do número, assimilando o segundo componente como "inteira e adequadamente conhecido". Cf. Bergson, Essai sur les données immédiates de la conscience, p. 57.

${ }^{29}$ François Heidsieck, ao discutir a concepção kantiana do conhecimento, afirma: "À metafísica, uma vez colocada entre os parênteses dos 'postulados', resta à concepção kantiana da ciência como a de uma 
acompanhamento da mobilidade interna do real, de seu inesgotável enriquecimento, a metafísica será concebida como um interminável inventário da experiência intuitiva. De igual maneira, por ser uma constante assimilação de dados empíricos sempre inconclusos, a ciência será, de direito, uma constante reelaboração da experiência sensível.

\section{Referências}

BARBARAS. Renaud. "Le tournant de l'expérience: Merleau-Ponty et Bergson". In: WORMS, Frédéric (org.). Philosophie: Henri Bergson. Paris: Les Édition de Minuit, 1997, p.33-59.

BERGSON, Henri. "Essai sur les données immédiates de la conscience". In: . Oeuvres (Édition du Centenaire). 6a ed. Paris: PUF, 2001a, p.1-157.

. "La pensée et le mouvant". In: - Oeuvres (Édition du Centenaire). $6^{\mathrm{a}}$ ed. Paris: PUF, p.1249-1482, 2001b.

. "L'energie spirituelle". In: . Oenvres (Édition du Centenaire). $6^{\mathrm{a}}$ ed. Paris: PUF, p.811-977, 2001c. . "Matière et mémoire". In: . Oeuvres (Édition du Centenaire). $6^{\mathrm{a}}$ ed. Paris: PUF, p.159-379, 2001d.

DELEUZE, Gilles. Bergsonismo. Tradução de Luiz B. L. Orlandi. São Paulo: Editora 34, 1999, 139p.

HEIDSIECK, François. Henri Bergson et la notion d'espace. Paris: PUF, 1961, 191p.

MARQUES, Silene Torres. "Significação da vida e liberdade: ciência e metafísica na filosofia de Bergson". In: Cadernos de História e Filosofia da Ciência, v. 13, 2003, p.81-94.

PRADO JR., Bento. Presença e campo transcendental: consciência e negatividade na filosofia de Bergson. São Paulo: Edusp, 1988, 223p. . Erro, ilusão, loucura: ensaios. São Paulo: Editora 34, 2004, 272p.

Matemática universal garantida pela Razão, um 'Deus formal'. A ciência permanece suspendida a uma dogmática: uma ciência fixada implica uma razão imutável; esta razão imutável, por sua vez, imobiliza a ciência em quadros fixos" (HEIDSIECK, 1961, p. 85-6). 
RODRIGUES, Paulo César. "Henri Bergson e a crítica à psicologia científica". In: Princípios, v.18, 2011, p.231-243.

SARTRE, Jean-Paul. A imaginação. Tradução de Paulo Neves. Porto Alegre: L\&PM, 2013, 143p.

SILVA, Franklin Leopoldo e. Bergson: intuição e discurso filosófico. São Paulo: Loyola, 1994, 357p.

WORMS, Frédéric.Bergson ou les deux sens de la vie. Paris: Quadrige/PUF, 2004, $361 \mathrm{p}$. Introduction à Matière et mémoire de Bergson. Paris: PUF, 1997, 330 p. 